\title{
Understanding cancer stem cell heterogeneity and plasticity
}

\author{
Dean G Tang ${ }^{1,2,3,4}$
}

${ }^{I}$ Department of Molecular Carcinogenesis, the University of Texas M.D. Anderson Cancer Center, Science Park, 1808 Park Rd. 1C, Smithville, TX 78957, USA; ${ }^{2}$ Program in Environmental \& Molecular Carcinogenesis, Graduate School of Biomedical Sciences (GSBS), Houston, TX 77030, USA; ${ }^{3}$ Centers for Cancer Epigenetics, Stem Cell and Developmental Biology, RNA Interference and Non-coding RNAs, and Molecular Carcinogenesis, the University of Texas M.D. Anderson Cancer Center, Houston, TX 77030, USA; ${ }^{4}$ Cancer Stem Cell Institute, Research Center for Translational Medicine, East Hospital, Tongji University, Shanghai 200120, China

Heterogeneity is an omnipresent feature of mammalian cells in vitro and in vivo. It has been recently realized that even mouse and human embryonic stem cells under the best culture conditions are heterogeneous containing pluripotent as well as partially committed cells. Somatic stem cells in adult organs are also heterogeneous, containing many subpopulations of self-renewing cells with distinct regenerative capacity. The differentiated progeny of adult stem cells also retain significant developmental plasticity that can be induced by a wide variety of experimental approaches. Like normal stem cells, recent data suggest that cancer stem cells (CSCs) similarly display significant phenotypic and functional heterogeneity, and that the CSC progeny can manifest diverse plasticity. Here, I discuss CSC heterogeneity and plasticity in the context of tumor development and progression, and by comparing with normal stem cell development. Appreciation of cancer cell plasticity entails a revision to the earlier concept that only the tumorigenic subset in the tumor needs to be targeted. By understanding the interrelationship between CSCs and their differentiated progeny, we can hope to develop better therapeutic regimens that can prevent the emergence of tumor cell variants that are able to found a new tumor and distant metastases.

Keywords: cancer stem cells; heterogeneity; plasticity; reprogramming

Cell Research (2012) 22:457-472. doi:10.1038/cr.2012.13; published online 17 January 2012

\section{Introduction}

Stem cells are cells with both self-renewing and differentiation abilities. Embryonic stem (ES) cells are pluripotent and, during development, can give rise to all cell types in the embryo proper. Adult stem cells are multipotent and can generate different lineages of progenitor cells that further differentiate into mature functioning cells. Adult stem cells, committed progenitors, and cells at various stages of differentiation constitute the kaleidoscope of cells in an adult organ and create what we call cellular heterogeneity.

Adult stem cells exist in organs with fast turnovers such as blood, small intestine, and epidermis as well as in organs generally considered 'post-mitotic' such as

Correspondence: Dean G Tang

Tel: 512-237-9575; Fax: 512-237-2475

E-mail: dtang@mdanderson.org brain, skeletal muscle, and prostate. Owing to their fast turnover nature, hematopoietic stem cells (HSCs) and stem cells in the intestinal and skin epithelia are among the best understood [1-3]. Stem cells and their lineage development in many adult organs with slower turnover rates are not well characterized, and therefore they are frequently termed stem/progenitor cells.

True stem cells with self-renewal capabilities are generally rare and located in a special microenvironment called niche, which is composed of various supporting (epithelial or stromal) cells, extracellular matrix, blood vessels, and nerve fibers [1-3]. Although stem cells can be proliferating or dormant, most primitive stem cells seem to be quiescent [1-4]. Whether dividing or dormant, an important functional characteristic of stem cells is that they possess significant proliferative potential that can be unleashed when needed. However, the most fundamental property of a stem cell is self-renewal, a term often over-used, inaccurately used, or misused, especially in the context of cancer stem cells (CSCs). The relationship 
between self-renewal and differentiation can be viewed using the scheme in Figure 1. Stem cells can have three modes of division: symmetric renewal, asymmetric cell division (ACD), and symmetric stem cell commitment. Self-renewal can either be ACD or symmetric renewal (Figure 1). However, ACD is most frequently used to assess self-renewal because the two daughter cells not only are phenotypically distinct but also take different developmental fates. In reality, the candidate stem cells either genetically tagged or labeled with a fluorescent dye, such as PKH26, are tracked under a time-lapse video microscope. During ACD, the two daughter cells differentially labeled can be identified and temporally followed (Figure 1). Like ACD, the other two division modes can also be recorded (Figure 1). In principle, adult stem cells can generate uni-, bi-, tri-, or even multipotent progenitors that further develop into specialized cells.

\section{Heterogeneity of normal stem/progenitor cells}

Most stem cells in adult tissues/organs are identified by cell surface markers. To demonstrate the functionality of the candidate stem cells, marker-purified (or enriched) cells are used in (syngeneic, allogeneic, or xeno-) transplantation assays to assess whether such cells can reconstitute or regenerate the tissues from which the cells are originated. A significant pitfall, often neglected, in such assays is that tissue transplantation represents a major trauma to the recipient animals and will initiate a woundhealing response. Consequently, host-cell contribution may confound the interpretations of stem cell-initiated tissue regeneration. An alternative to surface markerbased stem cell assays is to perform lineage tracing in animals using a reporter driven by 'stem cell-specific' gene promoters. Such reporter systems, once established, can definitively characterize true stem cell properties by following their development in vivo (i.e., in the animals). One caveat is that the lineage-tracing approach can only be used in lab animals and therefore, the relevance of the results to humans still needs to be validated by transplantation and in vitro assays.

In addition to the marker-enrichment and lineage-tracing strategies, stem cells can be identified by virtue of their quiescent and slow-cycling properties. Such cells, called label-retaining cells $[5,6]$, can now be purified out live in genetic models and used in functional assays [1]. Finally, stem cells can be enriched using the side population (SP) [7] and Aldefluor [8] assays, both of which take advantage of the preferential expression of detoxification molecules (e.g., $\mathrm{ABC}$ transporters such as $\mathrm{ABCG} 2$ in SP analysis) or enzymes (e.g., ALDH1A1 in Aldefluor assay) in adult stem cells.

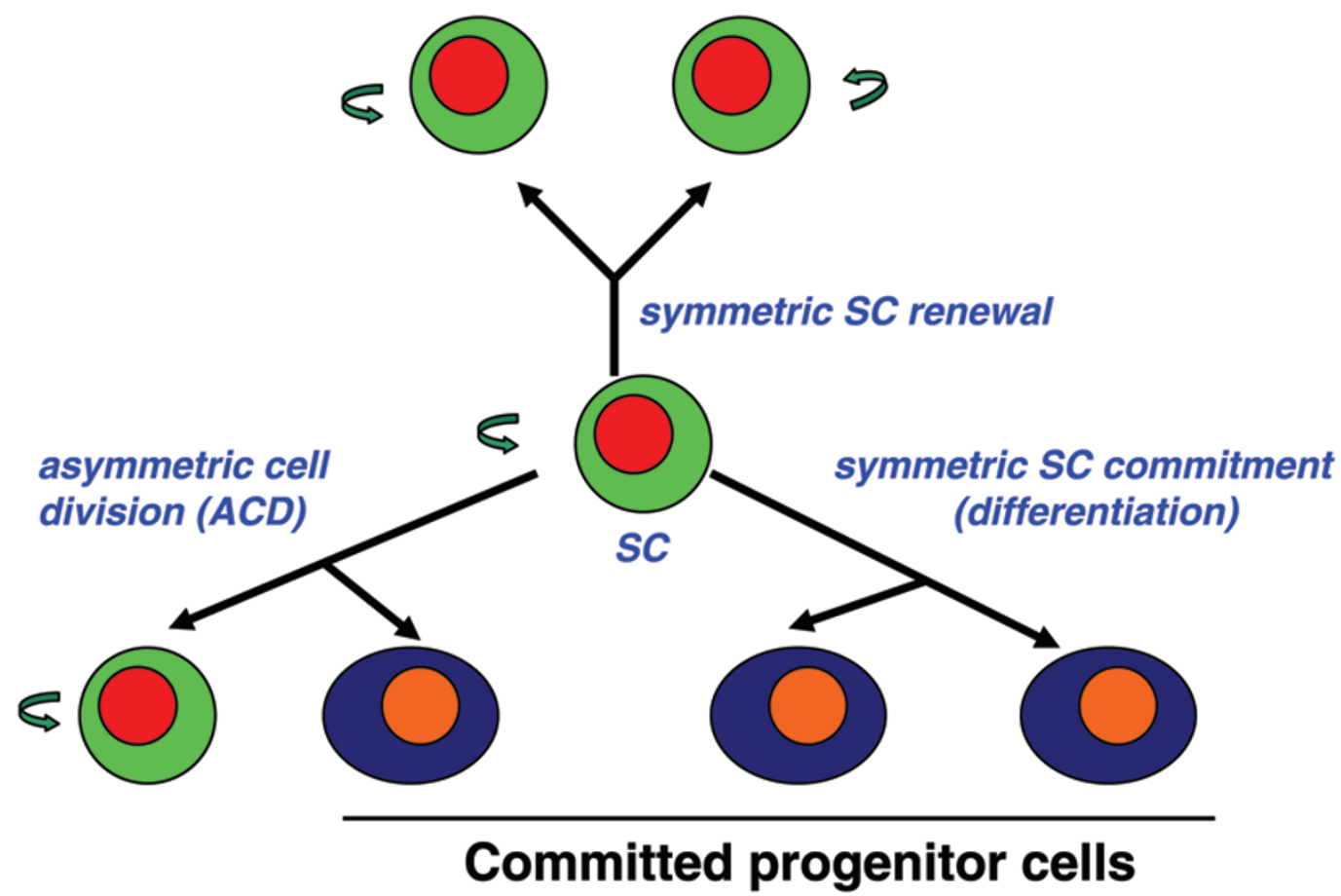

Figure 1 Relationship between stem cell self-renewal and differentiation (or commitment). The stem cell (SC) self-renewal is indicated by curved arrows. Only a uni-potent progenitor cell is depicted. See text for discussion. 
Regardless of the approaches used, the 'stem cell' population purified is heterogeneous containing a mixture of true stem cells and more mature progenitors. A good example is human HSCs [9], whose activity is operationally defined by lymphomyeloid engraftment that persists for $\geq 20$ weeks post transplantation [10]. The human HSCs, which are $\mathrm{Lin}^{-} \mathrm{CD} 38^{-} \mathrm{CD} 45 \mathrm{RA}^{-}$, should better be considered as a hematopoietic stem/progenitor cell pool in which multiple subsets of cells preferentially expressing surface markers, such as CD34 and/or CD90 (Thy-1), (Figure 2) are hierarchically organized. Although it has been known for quite some time that the $\mathrm{Lin}^{-} \mathrm{CD} 34^{+} \mathrm{CD} 38^{-}$blood cells contain HSCs, most CD $34^{+}$ cells are actually progenitor cells and the HSC activity can be enriched by CD90 [11]. Nevertheless, even the $\mathrm{Lin}^{-} \mathrm{CD} 34^{+} \mathrm{CD} 38^{-} \mathrm{CD} 45 \mathrm{RA}^{-} \mathrm{CD} 90^{+}$subpopulation has only $\sim 5 \%$ cells possessing long-term hematopoiesis-reconstituting activity compared to $\sim 1 \% \mathrm{Lin}^{-}$ $\mathrm{CD} 34^{+} \mathrm{CD} 38^{-} \mathrm{CD} 45 \mathrm{RA}^{-} \mathrm{CD} 90^{-}$cells having such activity [10]. The HSC activity can be again enriched using the $\mathrm{Lin}^{-} \mathrm{CD} 34^{+} \mathrm{CD} 38^{-} \mathrm{CD} 45 \mathrm{RA}^{-} \mathrm{CD} 90^{+} \mathrm{CD}^{-} 49 \mathrm{f}^{+}$marker profile with $9.5 \%$ ( 1 in 10.5) cells possessing the long-term repopulating property compared to $0.9 \%$ ( 1 in 111.3 ) $\mathrm{Lin}^{-} \mathrm{CD} 34^{+} \mathrm{CD} 38^{-} \mathrm{CD} 45 \mathrm{RA}^{-} \mathrm{CD} 90^{+} \mathrm{CD}^{-} 9 \mathrm{f}^{-}$cells having such activity [10]. The HSC activity can be further enriched using the 7 -marker $\mathrm{Lin}^{-} \mathrm{CD} 34^{+} \mathrm{CD} 38^{-} \mathrm{CD} 45 \mathrm{RA}^{-}$ $\mathrm{CD} 90^{+} \mathrm{Rho}^{10} \mathrm{CD} 49 \mathrm{f}^{+}$profile with $14 \%$ cord blood or $28 \%$ bone marrow marker-sorted cells possessing the longterm repopulating property in NOD-scid-IL $2 R \gamma c^{-1-}$ or NSG mice [10]. The extraordinary example of human HSCs illustrates that the hematopoietic stem/progenitor cells are quite heterogeneous (Figure 2). It can be imagined that if we have the ability to find the unique markers expressed in the most primitive HSCs and keep fractionating the progenitor pool, we should be able to uncover a very small population of HSCs in which every single cell would fulfill the most stringent HSC definition, i.e., single-cell engraftment, systemic hematopoietic reconstitution, and rescue of the lethally irradiated recipient animal [12].

Similar heterogeneity has also been observed in mouse HSCs. When using the $\mathrm{Lin}^{-/ \mathrm{lo}} \mathrm{c}-\mathrm{Kit}^{\mathrm{hi}} \mathrm{Sca}-1^{\mathrm{hi}} \mathrm{Thy} 1.1^{\mathrm{lo}} \mathrm{Flk}$ combinatorial markers, $\sim 0.02 \%$ (i.e., 1 out of 5000 ) mouse bone marrow cells can sustain lifelong selfrenewal [9]. However, when single cells bearing markers of $\mathrm{Lin}^{-} \mathrm{mCD} 34^{-1 \mathrm{lo}} \mathrm{c}-\mathrm{Kit}^{+} \mathrm{Sca}-1^{+}$were implanted, as many as $21 \%$ of the recipient animals sustained long-term lymphohematopoietic reconstitution [12]. Further, when using $\mathrm{Lin}^{-} \mathrm{c}-\mathrm{Kit}^{+} \mathrm{Sca}-1^{+} \mathrm{CD} 150^{+} \mathrm{CD} 48^{-}$as the purification marker, $20 \%-50 \%$ of bone marrow cells bearing the marker profile exhibit long-term reconstituting activity [13].
An example of stem cell heterogeneity in a nonhematopoietic organ is mouse prostatic stem cells, which were first enriched using the GPI-linked surface protein Sca-1 $[14,15]$. Cell-labeling experiments using green fluorescence protein-tagged Sca- $1^{+}$cells mixed with non-tagged cells demonstrate clonal origins for single prostatic tubules that contain both $\mathrm{p} 63^{+}$basal and $\mathrm{AR}^{+}$ luminal cells [14], suggesting the presence of bipotential progenitors in the Sca- $1^{+}$cell population. However, Sca$1^{+}$prostate cells are heterogeneous containing both stem and non-stem cells. Combinatorial marker profiling by adding CD49f (integrin $\alpha 6$ ) reveals that the $\mathrm{Lin}^{-} \mathrm{Sca}-$ $1^{+} \mathrm{CD} 49 \mathrm{f}^{+}$mouse prostate cells constitute $\sim 1 \%$ of total prostate epithelial cells, are localized predominantly in the basal layer proximal to the urethra, overlap $(\sim 70 \%)$ with the basal marker K5, and, importantly, exhibit much enhanced clonal growth and serial (i.e., renewing) sphere-forming potential in vitro as well as the ability to regenerate prostatic tubules when transplanted as tissue recombinants under the renal capsules [16]. Again, the regenerated tubules are of clonal origin and contain both basal (e.g., $\mathrm{K}^{+}$, p63 ${ }^{+}$) and luminal $\left(\mathrm{K} 8^{+}\right)$cells providing evidence for the existence (and identity) of bipotential normal mouse prostatic basal stem cells. Further

\section{Hematopoietic stem/progenitor cell pool (Lin-CD38-CD45RA')}

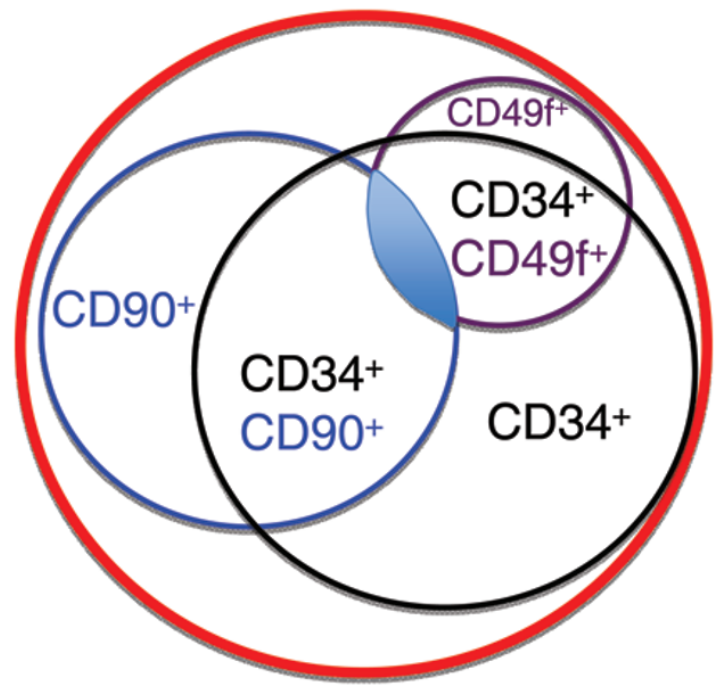

Figure 2 A cartoon depicting the heterogeneous nature of human hematopoietic stem/progenitor cell pool. Illustrated are three subsets (i.e., CD34 ${ }^{+}, \mathrm{CD} 90^{+}$, and $\mathrm{CD} 49 \mathrm{f}^{+}$) of progenitors inside the Lin-CD38-CD45RA ${ }^{-}$population. Combined sorting of triple marker-positive (i.e., CD $34^{+} \mathrm{CD} 90^{+} \mathrm{CD} 49 \mathrm{f}^{+}$; shaded) blood cells (in either bone marrow or cord blood) greatly enriches HSCs with long-term repopulating activity. 
purification using the $\mathrm{Lin}^{-} \mathrm{Sca}-1^{+} \mathrm{CD} 133^{+} \mathrm{CD} 44^{+} \mathrm{CD} 117^{+}$ marker profile reveals multipotent prostate stem cells in the basal compartment [17]. Immunostaining shows that the $\mathrm{CD} 117^{+}$(c-Kit, stem cell factor receptor) population is enriched proximal to the urethra, predominantly in the basal layer ( $\sim 3 \%$ of total basal cells). Fractionated $\mathrm{CD} 117^{+}$cells combined with rat UGSM (urogenital sinus mesenchyme) and transplanted under the kidney capsules can regenerate prostate-like structures comprising cells of the basal $\left(\mathrm{K} 14^{+}\right)$, luminal $\left(\mathrm{K} 18^{+}\right)$, and, for the first time, neuroendocrine (synaptophysin ${ }^{+}$) lineages, thereby demonstrating tripotency [17]. Single cell-reconstitution assays achieved successful engraftments in 14 of 97 single cell transplantations (along with rat UGSM). The single cell-derived outgrowths also contain all three principal prostate cell types (basal, luminal, and neuroendocrine), with luminal cells expressing the critical differentiation-related homeobox protein, $\mathrm{Nkx} 3-1$, and the terminal differentiation marker, probasin, suggesting that the reconstituted tubules possessed functional secretory activities [17].

These examples suggest that the term 'stem cells' in most cases is used very loosely and actually refers to a group of heterogeneous cells. It is imperative to bear in mind that stem cells must be functionally assayed by the 'stem cell activity'. To a certain degree, the enrichment of stem cells, or, more precisely, stem cell activity, and separation of stem cells from mature progenitors resemble a biochemical fractionation, in which homogeneous (i.e., high) enzymatic activity can be reconstituted by adopting either more extensive fractionation steps or a more 'specific' fractionation protocol. Stem cell heterogeneity may imply that distinct subsets of stem/progenitor cells are inter-related and thus hierarchically organized or different subpopulations are unrelated. Strictly speaking, however, if all self-renewing blood-generating cells are initially derived from a primitive HSC, all subsets should have the hierarchical relationship. That adult stem cells are heterogeneous should not be surprising as even cultured ES cells, usually thought as being homogeneous, actually contain partially committed neuronal and hematopoietic progenitors [18]. It may be of practical interest to point out that stem cell markers may be unique or conserved, across species and lineages. For example, Sca-1, which enriches both hematopoietic and prostatic epithelial stem cells in mouse, is not expressed in humans. On the other hand, c-Kit appears to enrich both mouse hematopoietic and prostatic epithelial progenitors whereas high levels of CD49f expression appear to be common to human hematopoietic and mouse prostate stem cells.

\section{Plasticity of normal stem cell progeny}

It is generally believed that during normal development or homeostasis, stem cells give rise to fast-proliferating progenitor cells that then mature into various types of functional cells (Figure 3A). In other words, this developmental path is usually a one-way 'traffic' under physiological conditions with fully differentiated cells being unable to proliferate or 'dedifferentiate' (Figure 3A). This unidirectionality of development, enforced by epigenetic mechanisms in and post-mitotic nature of most terminally differentiated cells guarantees that different cell types in an organ have distinct identities and play specialized functions. For instance, neurons, skeletal muscle cells, and fibroblasts in adult organs rarely divide. Adult human cardiomyocytes are mostly postmitotic with a turnover rate of $\sim 1 \%$ per year at age 20 and $0.4 \%$ per year at age 75 . At age $50,55 \%$ of human cardiomyocytes remain from birth and over the first decade of life, cardiomyocytes often undergo a final round of DNA synthesis and nuclear division without cell division, resulting in $\sim 25 \%$ of human cardiomyocytes being binucleated [19]. Similarly, the average lifespan of human adipocytes is $\sim 10$ years and the number of fat cells in adult humans remains quite constant with an annual turnover rate of only $\sim 10 \%[20,21]$. The post-mitotic nature of terminally differentiated cells would suggest that dedifferentiation, a process thought to be genetically regulated $[22,23]$ in which a specialized cell takes on a more primitive state, although representing one potential aspect of plasticity in the stem cell progeny, may not take place prevalently under homeostatic conditions in adult mammalian organs (Figure 3A).

On the other hand, not all mature cells are post-mitotic and differentiated cells may retain the ability to generate more differentiated cells. For example, endothelial cells (ECs), hepatocytes, and Schwann cells are known to retain significant proliferative potential. Certain differentiated cells such as pancreatic endocrine insulin-producing $\beta$-cells are able to duplicate themselves under homeostatic conditions [24] (Figure 3B, top). Self-duplication of mature cells represents another potential route of plasticity in the stem cell progeny.

Most cell plasticity occurs in response to injuries or upon experimental manipulations (Figure 3B-3G). One type of cell plasticity involves generation, from differentiated cells, of more differentiated cells of the same or different lineages (Figure 3B-3D). For example, pancreatic $\beta$-cell self-duplication increases significantly upon experimentally induced organ damage [24] (Figure 3B, bottom). Genetic deletion of Pax5 (paired box gene 5) leads to dedifferentiation of mature B cells to uncom- 


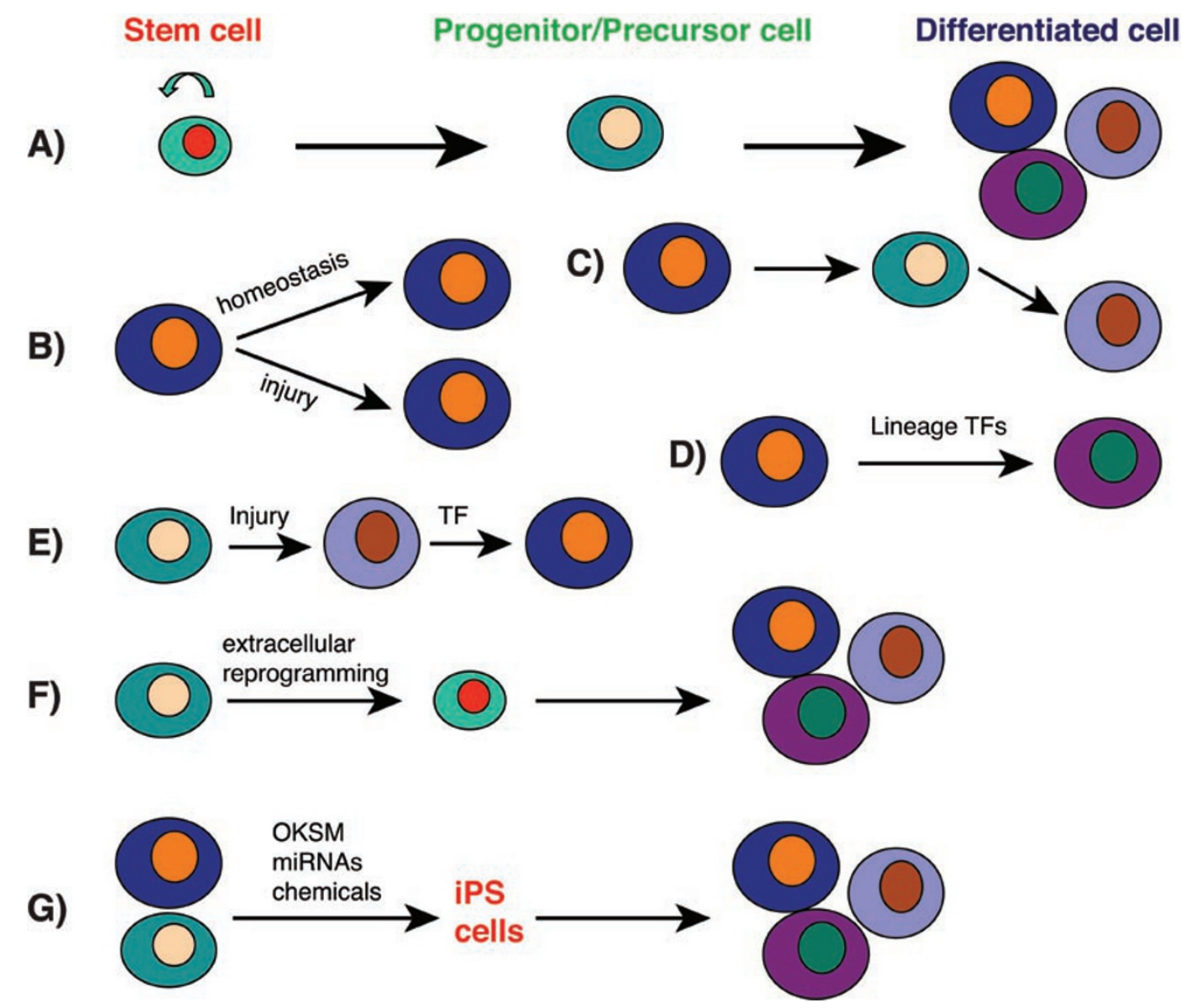

Figure 3 Stem cell development under normal (physiological) conditions (A) and different forms of plasticity of the stem cell progeny during injury and upon induction (B-G). In (A), a self-renewing, relatively quiescent stem cell gives rises to a proliferative progenitor cell (sometimes called a precursor cell), which then develops into non-proliferative terminally differentiated cells. Stem cells, progenitors, and differentiated cells are illustrated in different colors and sizes. As an example, this progenitor cell is depicted to generate three different differentiated cells. (B) A differentiated cell directly generates another differentiated cell of the same type. The best example is mouse pancreatic $\beta$-cells. (C-D) Plasticity by which one differentiated cell type is converted (C) or directly converts (D) to another differentiated cell type. (E) A progenitor cell gives rise to a specialized cell type upon injury, which is then transdifferentiated into another specialized cell type by a lineage-specific TF. (F-G) Plasticity by which progenitor (or differentiated) cells are reprogrammed to a more primitive cell, which then develops into various specialized cells. See text for individual examples.

mitted early progenitors that then differentiate into $\mathrm{T}$ lymphocytes [25], illustrating cellular dedifferentiation induced by manipulating lineage-specific transcription factors (TFs) (Figure 3C). More often and very excitingly, overexpression of lineage-specific TFs is found to be capable of directly reprogramming different cell fates [26-34]. It was first shown that three TFs (i.e., Ngn3, $\mathrm{Pdx} 1$, and Mafa) were sufficient to reprogram pancreatic exocrine cells to $\beta$ cells [27]. Recently, direct reprogramming of fibroblasts into neurons [30-32] or hepatocytes $[33,34]$ has also been achieved using respective lineage TFs. Of note, in all such experiments [27, 30-34], plasticity is induced and cell fate reprogramming is achieved by directly turning one differentiated cell type to another (Figure 3D), a process often termed cellular transdifferentiation.

Another type of induced plasticity involves progenitor cells (Figure 3E-3G). In response to injury, a population of pancreatic progenitors can generate glucagonexpressing $\alpha$ cells, which then, with ectopic expression of Pax4, transdifferentiate into $\beta$ cells [35]. This example illustrates one special type of cellular transdifferentiation in which injury turns progenitor cells into one specialized cell type, which is transdifferentiated into another specialized cell type upon the action of a lineage-specific TF (Figure 3E). Another example of progenitor cell 
plasticity is offered by oligodendrocyte precursor cells, which can be reprogrammed by extracellular signaling molecules into neural stem cells that then develop into astrocytes, oligodendrocytes, and neurons [36]. The ultimate example of cellular reprogramming is induced pluripotent stem (or iPS) cells, which are derived from direct reprogramming of differentiated cells or progenitors by overexpressing pluripotency factors (i.e., OKSM or Oct-4, KLF4, SOX2, and Myc) or by using miRNAs or chemicals [29, 37] (Figure 3G). iPS cells resemble ES cells and thus possess the potential to generate all different types of cells. iPS cells or direct cell reprogramming using lineage-specific TFs hold great promises for generating specific cell types needed for cell therapy. Potential problems are associated with incomplete reprogramming and retention of donor cell memory.

In summary, the stem cell progeny retain significant plasticity that can manifest in response to injuries or upon experimental inductions, which can be employed to generate precious cell types for cell therapy. However, such plasticity may not occur prevalently in normal tissues under homeostatic conditions.

\section{CSCs}

Tumorigenesis has been long known to resemble organogenesis and most tumors are heterogeneous containing many phenotypically and functionally different cells. Tumor cell heterogeneity may result from clonal evolution driven by genetic instability and/or from maturation/ differentiation of stem-like cells frequently called CSCs or tumor-initiating cells [38]. Recent evidence indicates that clonal evolution and CSC-directed development may not necessarily be mutually exclusive and both mechanisms may cooperate to create tumor cell heterogeneity $[39,40]$. Although there are still debates about the CSC concept and some CSCs reported, there is no denying that malignant tumors are immortal at the population level. It will be interesting and important to identify and characterize the immortal subpopulations of cancer cells.

The subject of CSCs is controversial not because CSCs do not exist, but because misconceptions and inadequate assays have caused many confusions and inconsistencies. First, CSC is a functional definition. Just as normal stem cells are measured by the stem cell activity, CSCs should be defined in functional assays by their ability to generate serially transplantable tumors that, at least partially, recapitulate the cellular and histostructural heterogeneity of the parent tumor. Simple marker expression and in vitro assays are not sufficient to define any cancer cells as CSCs. Furthermore, many of the CSCs so far reported have not been subjected to series trans- plantation assays; instead, only tumor incidence and/or tumor weight are used to measure the CSC activity. Such endpoints may well be assaying tumor progenitor rather than CSC activity due to the high proliferative capacity in the progenitor cell population (Figure 4). Serial tumor transplantation assays, especially at low cell doses, should allow the demarcation of long-term CSCs vs fastproliferating tumor progenitors, both of which possess tumor-initiating capacities.

Second, CSCs may or may not originate from normal stem cells [41]. In fact, because progenitor cells generally represent the largest proliferative pool in an organ they theoretically could represent the best transformation targets (Figure 4). In this scenario, the transformed progenitors acquire self-renewal capacity, become the CSCs, and establish clinical tumors. Unfortunately, in the literature, very often CSCs are said to originate from normal stem cells. A good example for this point comes from analyzing the potential transformation target in basal-like human breast cancers [42]. The authors employed a combination of surface markers to purify out basal stem/progenitor (CD49f ${ }^{\text {hi }}$ EpCAM ${ }^{-}$; expressing p63/CK14/vimentin but not ER/PR), luminal progenitor (CD49f $\mathrm{EpCAM}^{+}$; expressing high levels of CK8/18/ER/MUC-1/GATA-3), and mature luminal (CD49f EpCAM ${ }^{+}$; expressing high levels of ER/PR) cells from normal mammary tissue and preneoplastic specimens from individuals heterozygous for a $B R C A 1$ mutation. BRCA1 mutations have been clinically linked to the development of basal-like breast cancers. Surprisingly, the BRCA1-mutant samples display a significant reduction in $\mathrm{CD} 49 \mathrm{f}^{\text {hi }} \mathrm{EpCAM}^{-}$basal stem cells, but a dramatic increase in $\mathrm{CD} 49 \mathrm{f}^{\dagger} \mathrm{EpCAM}^{+}$luminal progenitor cells. These observations, together with subsequent gene expression profiling and functional studies, suggest that an aberrant luminal progenitor population may represent the transformation target in $B R C A 1$-associated basal breast tumors [42]. Independent studies in mouse genetic models by deleting Brcal in either basal stem or luminal progenitor cells verified that only Brcal deletion in the luminal progenitor compartment phenotypically and histologically recapitulates the human basal-like breast cancers [43]. Interestingly, mammary epithelial cells derived from $B R C A^{\mathrm{mut} /+}$ patients give rise to tumors with increased basal differentiation relative to $B R C A^{+/+}$cells [44], suggesting that specific genetic mutations may dictate the phenotypic fate of progenitor cells during tumor development.

Third, the initially transformed cells may not be the cell-of-origin (i.e., CSCs or cancer-initiating cells) for the clinical tumor. The transformed cell may remain dormant for decades without generating a clinically detectable tumor. Recent studies using elegant MADM (mosaic 


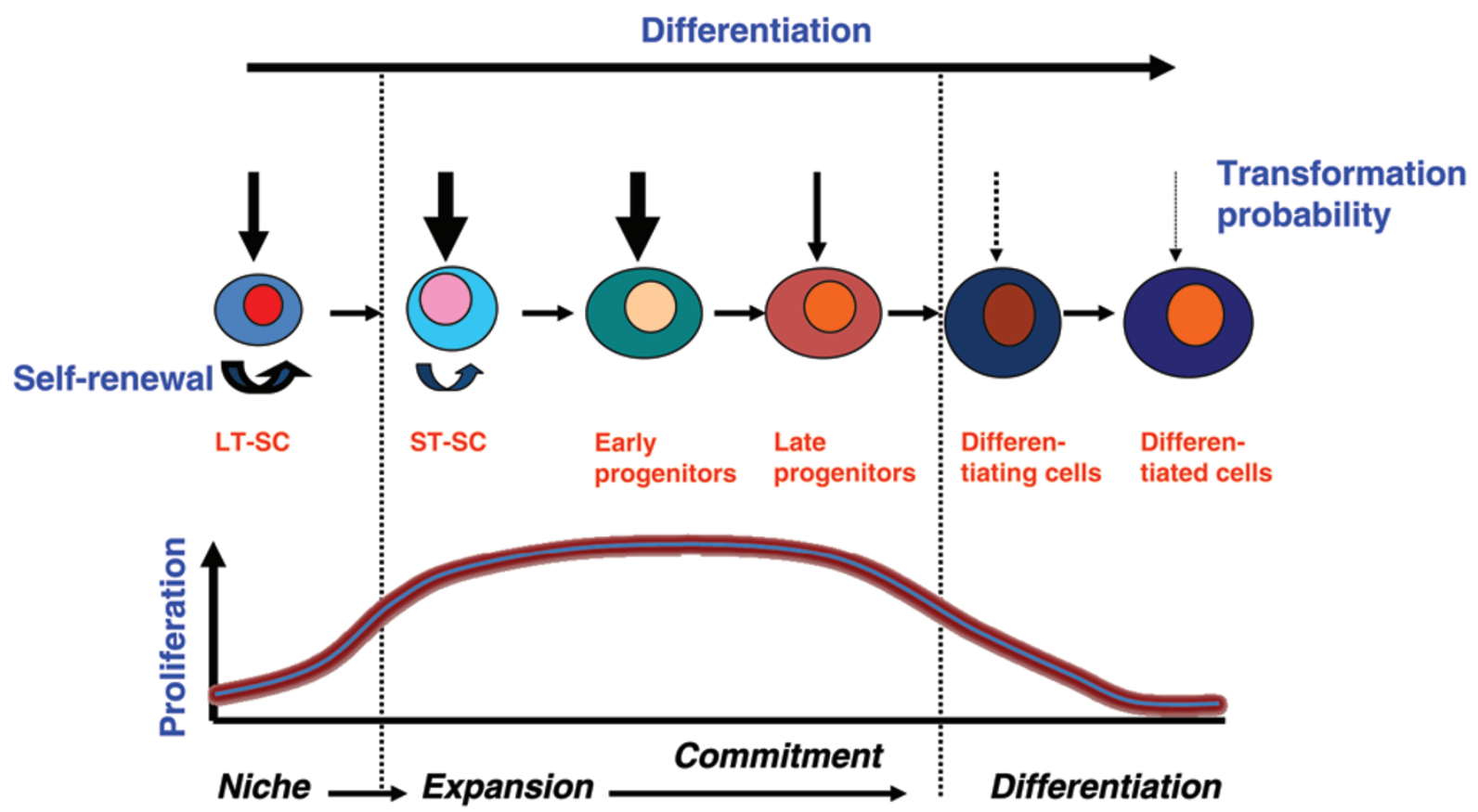

Figure 4 Stem cell proliferation, self-renewal, differentiation, and transformation. Depicted here is a hypothetical long-term stem cell (LT-SC), which has the greatest self-renewal activity and is quiescent in its niche (bottom). LT-SC develops into a short-term stem cell (ST-SC), which shows reduced self-renewal activity but increased proliferation. The ST-SC then gives rise to early progenitor cells that may have lost self-renewal capacity, but probably represent the most proliferative cell population. Early progenitors generate late progenitor cells that begin to commit to differentiate by expressing lineage-specific differentiation markers and these late progenitor cells gradually develop into fully differentiated cells that once again lose proliferative potential (i.e., post-mitotic). From the standpoint of transformation probability, the ST-SC that retains self-renewal activity and progenitor cells that are highly proliferative (demarcated by two vertical thick lines) theoretically could represent the best targets for tumorigenic transformation.

analysis using double markers) mouse models provide strong support for this scenario by showing that the oligodendrocyte precursor cells represent the cell-of-origin for malignant gliomas, although the initial transformation occurs in all neural and glial progenitors [45]. Fourth, as CSCs are in most cases defined, operationally, as tumorinitiating cells and because the current CSC assays have inherent limitations (e.g., relying heavily on xenotransplantations), the reported CSCs may not necessarily be the same as the founding cells that gave rise to patient tumors in vivo. This point is important also when considering that in vivo, CSCs may differ between different patient tumors and may constantly change as the disease progresses.

Fifth, CSCs may or may not be rare [46, 47], and their relative abundance likely varies with individual patient tumors, tumor type, grade, and treatment status. This is a critical point as it has been mistakenly assumed (and presumed) by many that CSCs must be rare. Also, the abundance of CSCs may not correlate strictly with poor clinical features in every tumor; however, it should theo- retically correlate with the levels of differentiation and malignancy. In other words, the more malignant a tumor is, the more stem-like cancer cells it may harbor. A priori, this logic makes sense as more malignant tumors contain more undifferentiated tumor cells, and CSCs are usually less differentiated or undifferentiated. Consistent with the undifferentiated nature of CSCs, early embryonic markers such as SSEA-1, TRA-1-60, and oncofetal protein 5T4 have been employed to enrich CSCs (see discussions below). Sixth, CSCs, though possessing some stem cell properties, are, nevertheless, transformed cells with complex genetic mutations and epigenetic alterations so they should not be equated to normal stem cells with respect to their biological properties. For instance, unlike normal stem cells, CSCs may not be able to undergo normal or complete differentiation. As such, some assays for normal stem cells may not be applicable to CSCs. For example, not all CSCs may be able to undergo multi-lineage differentiation. Seventh, it should be born in mind that mice, despite their wide use and great value in biomedical and cancer research, are different from 
humans and normal stem cells in the human and the corresponding mouse organs may be phenotypically different, as illustrated above by HSCs. Consequently, CSCs in human and rodent tumors may also be phenotypically distinct. Frequently, results from the two experimental systems are mixed up, thus creating confusions. Lastly, like normal stem cells, CSCs are heterogeneous and their progeny may also possess plasticity, especially accompanying tumor progression and in response to therapeutic interventions, which I discuss below by focusing on CSCs in human tumors.

\section{CSC heterogeneity}

CSCs, now reported in most human tumors, are commonly identified and enriched using strategies for identifying normal stem cells, which include flow cytometrybased sorting using cell surface markers, such as CD44 and CD133, and functional approaches, including SP analysis [7], Aldefluor assay [8, 48], and sphere formation coupled with serial sphere passaging [49]. The CSCenriched populations prospectively purified using these strategies are then implanted, at various cell doses, in immune-deficient mice to assay their tumor-regenerating capacity, an in vivo assay often called limiting dilution assay. The tumor cell subset that can initiate tumor development at low cell numbers is enriched in CSCs, and these cells are further tested for 'self-renewal' capacity in serial tumor transplantations when feasible.

Interestingly, much like the heterogeneity of normal stem cells in an adult organ, CSCs in the same type of human cancer are phenotypically and functionally heterogeneous. Breast CSCs (BCSCs) are the first CSCs to be reported in solid tumors and are among the most intensely studied. Human BCSCs have been enriched in $\mathrm{CD} 44^{+} \mathrm{CD} 24^{-/ 10}[50], \mathrm{SP}[51,52], \mathrm{ALDH}^{+}[53,54]$, and PKH26 dye-retaining [55] cells. Although the interrelationships between these different subsets of tumorigenic BCSCs remain unclear, these observations [49-55] suggest that human BCSCs are phenotypically diverse. Indeed, recent studies [53-59] indicate that not only CSC marker expression in breast cancer cells is heterogeneous but also there exist many subsets of BCSCs that vary from patient to patient, which may be related to individual tumor's genetic makeup [44]. The enrichment of BCSCs by different approaches also suggests that different phenotypes may identify overlapping tumorigenic populations and consequently, certain combinatorial strategies might further enrich tumor-initiating cells. For example, although there is only a small overlap between $\mathrm{ALDH}^{+}$(i.e., cells expressing high levels of aldehyde dehydroganse (ALDH) activity measured by the Alde- fluor assays; sometimes called $\mathrm{ALDH}^{\text {bri }}$ or $\mathrm{ALDH}^{\mathrm{hi}}$ ) and $\mathrm{CD} 44^{+} \mathrm{CD} 24^{-/ 10}$ cells, the cells bearing two phenotypes (i.e., $\mathrm{ALDH}^{+} \mathrm{CD} 44^{+}$) seem to be more tumorigenic than cells expressing either marker alone [53]. A recent study provides further support to these points. In ER $\alpha$-negative human breast cancer, xenograft-initiating cells are found in both $\mathrm{CD} 44^{+} \mathrm{CD} 24^{-}$and $\mathrm{CD} 44^{+} \mathrm{CD} 24^{+}$cell populations; however, CSCs are most highly enriched using the combinatorial marker profile $\mathrm{CD} 44^{+} \mathrm{CD} 49 \mathrm{f}^{\text {hi }} \mathrm{CD} 133 / 2^{\text {hi }}$ [59]. BCSCs are among the few CSC types that have been shown to undergo both ACD and symmetric renewal (Figure 1). Using the ErbB2 breast cancer model and PKH26 dye retention/dilution strategy, Cicalese et al.[60] demonstrate higher symmetric renewal divisions in $\mathrm{BC}$ $\mathrm{SCs}$ than in their normal counterparts. Interestingly, p53 deficiency in normal mammary stem cells increases symmetric cell divisions, thus predisposing to tumor development [60].

CSCs have been reported in brain tumors, especially in glioblastoma multiforme (GBM) [61-74]. The stemlike GBM cells have been enriched using cell surface molecules, such as CD133 [61, 72], SSEA-1 (stagespecific embryonic antigen-1) [64], EGFR [67, 68], and CD44 [69], or functional assays, including the SP analysis $[7,63,73]$ and neurosphere assays $[49,74]$. Intriguingly, there are significant uncertainties surrounding the use of CD133 as a marker for brain tumor stem cells (BTSCs). Although CD133 has been widely utilized to enrich BTSCs $[61,72]$ and molecular profiling has revealed stem cell gene expression patterns associated with CD133 ${ }^{+}$GBM cells [71], tumorigenic cells are found in both $\mathrm{CD} 133^{+}$and $\mathrm{CD} 133^{-}$cells in some gliomas [62], and some $\mathrm{CD} 133^{+}$brain tumor cells may not possess high tumor-initiating capacity, and, in fact, the CD133 cell population from some GBM may actually harbor long-term self-renewing tumor-initiating cells [66]. Similarly, the SP may or may not enrich BTSCs $[63,73]$. Furthermore, although it has been reported (or assumed) that there exists a lineage relationship between $\mathrm{CD} 133^{+}$and CD133- brain tumor cells, the two populations of cells may have different cells-of-origin [70]. More studies are required to resolve these contradictory findings. Chen et al.[66] propose that GBMs contain multiple distinct populations of linearly related CD133- cells representing different stages of differentiation with some $\mathrm{CD} 133^{-}$cells generating aggressive tumors containing both $\mathrm{CD} 133^{+}$ and $\mathrm{CD} 133^{-}$cells and some other $\mathrm{CD} 133^{-}$cells, perhaps by symmetric stem cell renewal, generating slow-growing circumscribed tumors of $\mathrm{CD} 133^{-}$cells. One point is clear and consistent: human malignant gliomas are extremely heterogeneous and harbor multiple distinct pools of self-renewing BTSCs capable of initiating phenotypi- 
cally diverse and serially transplantable tumors.

Multiple CSCs have also been reported in human colon cancer [75-86] using cell surface markers CD133 [75-77], CD44 [78, 79] or ABCB5 [85], clonal analysis [80], SP phenotype [84], and Aldefluor assays [82]. As in studies of BTSCs, use of CD133 as a positive selection marker for colon CSCs has generated conflicting results $[75-77,81]$, but subsequent studies indicate that the AC133 epitope, but not CD133 protein, is differentially and specifically expressed in colon CSCs and its expression is lost upon differentiation [83]. On the other hand, CD $44^{+}$cells seem to consistently enrich tumorigenic colon cancer cells and additional subfractionation of the $\mathrm{CD} 44^{+} \mathrm{EpCAM}^{+}$cell population with $\mathrm{CD} 166$ further enhances the success rate of tumor engraftments [78]. ALDH has also been used as a marker for colon CSCs, but $\mathrm{ALDH}^{+}$colon cancer cells are still heterogeneous and further enrichment using CD44 or CD133 significantly increases the tumor-initiating capacity [82].

Similarly, stem-like cancer cells have been reported in human cancers of the prostate [87-100], lung [101111], and many other organs (liver, pancreas, kidney, bladder, ovary, etc). In prostate cancer, tumor-initiating cells have been identified in xenografts in $\mathrm{CD}_{4} 4^{+}[90$, 96], $\mathrm{CD}_{4} 4^{+} \alpha 2 \beta 1^{+}$[91], TRA-1- $60^{+} \mathrm{CD} 151^{+} \mathrm{CD} 166^{+}$[99], and $\mathrm{ALDH}^{+}[97,98]$ populations as well as in SP [87] and holoclones [94]. The interrelationship between these tumorigenic subsets remains currently unclear except that the $\mathrm{CD} 44^{+} \alpha 2 \beta 1^{+}$phenotype greatly enriches tumorinitiating cells compared to $\mathrm{CD} 44^{+}$phenotype alone [91]. Although $\mathrm{CD} 133^{+} \mathrm{CD} 44^{+} \alpha 2 \beta 1^{+}$(i.e., triple markerpositive) cells in primary prostate tumors are highly clonogenic [89], whether such cells are endowed with enhanced tumor-initiating capacity is unknown. In fact, one of the major unanswered questions is whether primary human prostate tumors, which do have cells expressing the above-mentioned markers, harbor authentic CSCs, mainly due to the technical difficulties in reconstituting human prostate tumors in immune-deficient mice when using fractionated single tumor cells. Putative lung CSCs have been reported in SP [101] and CD133 ${ }^{+}$[102-104, 108], $\mathrm{ALDH}^{+}$[107], $\mathrm{CD}_{4} 4^{+}$[109], and oncofetal protein $5 \mathrm{~T}^{+}[111]$ cells. Again, the interrelationship between these tumorigenic subpopulations is presently unclear.

How should we understand the complicated picture of CSC heterogeneity? First of all, since normal stem cells are heterogeneous and stem/progenitor cell development is a continuum, it should not come as a surprise that CSCs are heterogeneous, especially when put in the context that CSC activity is only defined, in a rather crude way, as enhanced tumor-initiating capacity. Second, in fact, leukemic stem cells (LSCs) in acute myeloid leukemia (AML), the best-characterized CSCs, are very heterogeneous. The AML LSCs were first reported to bear the $\mathrm{CD} 34^{+} \mathrm{CD} 38^{-}$normal HSC marker profile with $\mathrm{CD} 34^{+} \mathrm{CD} 38^{+}$and $\mathrm{CD} 34^{-}$fractions containing no clonogenic and leukemia-initiating cells based on engrafting assays in SCID mice $[112,113]$. It was found, 10 years later, that true $\mathrm{LSCs}$ in the $\mathrm{CD} 34^{+} \mathrm{CD} 38^{-}$fraction were very rare and comprised a hierarchy of cells with different self-renewal potential [114]. Recent xenotransplantation studies in NSG mice confirmed the rarity of LSCs $(\sim 1$ per $\left.0.15-4.1 \times 10^{6}\right)$, but revealed more unexpected heterogeneity of SCID leukemia-initiating cells, which were found not only in $\mathrm{Lin}^{-} \mathrm{CD} 38^{-}$fraction but also in $\mathrm{CD} 34^{-}$, $\mathrm{Lin}^{+}, \mathrm{CD} 38^{+}$, and CD45RA ${ }^{+}$fractions [115]. Importantly, the new study [115] indicates that the AML LSCs do not necessarily derive from the normal HSCs as initially hypothesized $[112,113]$, emphasizing the potential disconnect between CSCs and normal stem cells.

Third, CSC heterogeneity refers mostly to phenotypic heterogeneity and, in most cases, it is unclear whether phenotypically diverse CSC populations are also functionally distinct. To address this relationship, one needs to use the same tumor (cell) system to simultaneously compare the tumorigenic potential of different subsets. In theory, various CSC populations may or may not be hierarchically organized, analogous to how cancer cells in general may be organized. In a hierarchical model, the most 'primitive' CSCs would develop into more mature tumor progenitors, which in turn develop into much less tumorigenic cells. These functionally divergent tumorigenic subsets can be dissected by serial transplantations coupled with clonal tracking, as done in analyzing AML LSCs [114]. In this scenario, if the most primitive CSC population is therapeutically targeted, all tumorigenic cells should be eliminated. On the other hand, multiple CSC subsets in a tumor may exist in a tumorigenic pool of undifferentiated cells, have different origins, and are not related to one another lineage-wise. Several pieces of evidence support the co-existence of independent $\mathrm{CSC}$ clones. In breast cancer, although the $\mathrm{CD} 44^{+} \mathrm{CD} 24^{-}$ cell population is enriched with progenitor cells and the $\mathrm{CD} 24^{+}$population is luminally differentiated, in some tumors a lineage relationship does not exist between CD24 and CD24 $4^{+}$epithelial cells as the two populations harbor different genetic alterations [116, 117]. Similarly, $\mathrm{CD}_{133^{+}}$and $\mathrm{CD} 133^{-}$glioma cells may have different cells-of-origin [70]. There is evidence that the primary tumor genotypes dictate the overall phenotypes of tumor progenitors $[44,66,110]$. It is conceivable that more mature tumor-initiating cells derived from the primitive CSCs may sustain secondary genetic hits and in turn become new CSCs, and then develop independently of the 
original CSCs. In reality, both hierarchical tumor-initiating populations and independently evolving tumorigenic clones may operate to create the heterogeneity of CSCs [80].

Finally, plasticity in CSCs and their progeny will further contribute to cancer cell and CSC heterogeneity [118], which I discuss below.

\section{Intrinsic and induced plasticity in CSC progeny}

As discussed earlier, terminally differentiated normal cells, in their natural milieu, generally do not manifest significant plasticity although they possess such potential. During early tumor development and in established tumors under unperturbed conditions, stem-like cancer cells perhaps mainly undergo one-way maturation by developing into tumor progenitors and even differentiated tumor cells (i.e., non-CSCs) (Figure 5A). In other words, developing tumors (or evolving tumor clones) may contain highly tumorigenic undifferentiated CSCs that would develop into phenotypically differentiated tumor cells that functionally possess low or no tumor-regenerating capacity (Figure 5A). Many examples of CSCs discussed in the preceding section in multiple tumor systems have been shown to be generally much less differentiated. For example, although LSC activity has been detected in several cellular compartments, the most tumorigenic subpopulation is still in undifferentiated $\mathrm{Lin}^{-} \mathrm{CD} 34^{+} \mathrm{CD} 38^{-}$cells, which can develop into more mature, less tumorigenic cells $[112,113,115]$. Likewise, in marker-independent sphere- (e.g., neurosphere, mammosphere, colonosphere, prostasphere, etc) formation assays, it has been repeatedly demonstrated that a single (undifferentiated) tumor cell can generate a sphere that contains multiple types of lineage-differentiated cells $[49,61,66,76,80,90,95$, $100,106]$. CD $133^{+}$colon CSCs can grow exponentially for more than a year as undifferentiated tumor spheres in vitro but, upon transplantation in vivo, they can generate tumors that histologically recapitulate the morphological and antigenic pattern of the original tumor [76]. These considerations would argue that undifferentiated tumor cells are in general more tumorigenic than their partially differentiated progeny. These discussions also suggest that in untreated (unperturbed) tumors, dedifferentiation of non-CSCs to CSCs may be rather low (Figure 5A). On the other hand, unlike normal organs, tumors lack the normal social control and suffer varying degrees of defects in normal differentiation pathways and, consequently, cancer cells in general display higher intrinsic or spontaneous morphological, phenotypic, and functional plasticity compared to fully differentiated normal cells (Figure 5B). One such plasticity is the phenomenon of 'molecular mimicry' (Figure 5B, left), in which poorly differentiated cancer cells (presumably CSCs or tumor progenitors) in melanoma, prostate cancer, sarcoma, and some other tumors can 'transdifferentiate' into cells resembling ECs, which organize into vessel-like structures that can even allow blood flow [119, 120]. Recent work indicates that defined CSCs in GBM can also transdifferentiate into EC (Figure 5B, right) where both cell types possess the same genetic mutations [121, 122].

There are potentially other forms of spontaneous cancer cell plasticity in addition to transdifferentiation. For example, a subpopulation of reversibly drugtolerant cancer cells has been detected in drug-sensitive non-small cell lung cancer cell cultures [123]. This subpopulation can arise de novo and is maintained by IGF1 receptor signaling and through epigenetic mechanisms involving the histone demethylase KDM5A (Jarid1A). Interestingly, this subpopulation of drug-tolerant cancer cells overlaps with, but is not identical to, CD133 CSCs [123], suggesting that not all drug-resistant cancer cells are CSCs [124]. It remains to be seen whether such reversibly drug-tolerant cancer cells exist in vivo and whether they bear stable and unique phenotypic markers that allow prospective identification. Recently, evidence has been provided [125] or it has been hypothesized [126] that non-CSCs and CSCs can inter-convert and nonCSCs can 'dedifferentiate' into CSCs (Figure 5A). This should not be surprising based on the discussions above. In fact, this phenomenon has been demonstrated in other systems, e.g., the inter-conversions between $\mathrm{ABCG}^{+}$and ABCG2 ${ }^{-}$prostate and breast cancer cells [87] or between $\mathrm{CD}_{4} 4^{+}$and $\mathrm{CD} 44^{-}$prostate cancer cells [90]. However, as discussed above, the rate of spontaneous conversion of non-CSCs to CSCs is probably very low and the kinetics of dedifferentiation is slow (Figure 5A). It should also be noted that most studies so far that reported on the spontaneous plasticity of non-CSCs have been performed in vitro.

Analogous to the induced plasticity in normal stem cell progeny (Figure 3), plasticity of non-CSCs perhaps occurs more prevalently under 'induced' conditions, e.g., accompanying tumor progression in vivo (Figure 5C) or as a result of experimental manipulations in vitro or therapies in vivo (Figure 5D). Hence, to a certain degree, cancer cell plasticity resembles fate reprogramming in differentiated normal cells. As tumors grow, tumor cells increasingly experience hypoxia and microenvironmental changes. Furthermore, there is increasing infiltration of inflammatory cells and accumulation of cytokines, chemokines, and other bioactive molecules such as interleukins (IL-1, IL-6, etc) and TGF- $\beta$, which may cause epithelial-mesenchymal transition (EMT). Conceivably, 
A) Early stages of tumor development Under 'normal' conditions

CSCs

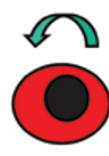

Progenitors

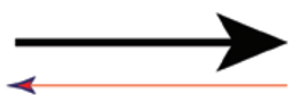

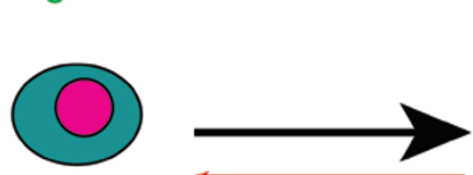

Non-CSCs;

Differentiated tumor cells

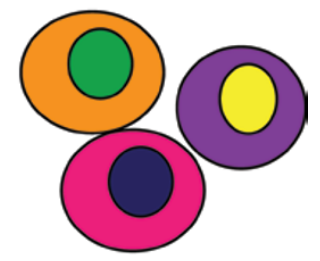

B) 'Intrinsic' plasticies in undifferentiated tumor cells and CSCs

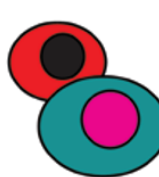

molecular
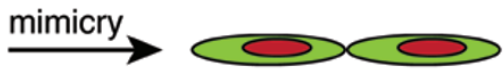

EC

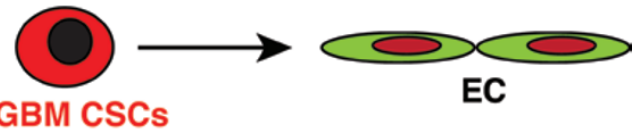

C)
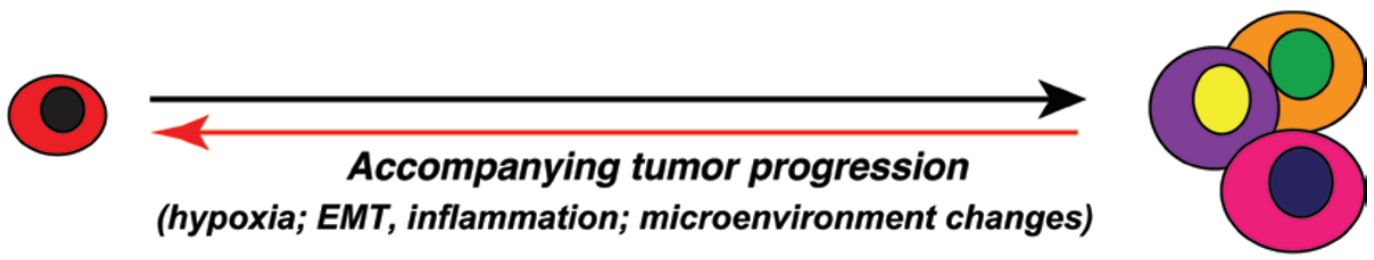

D)
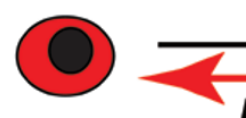

\section{Experimental manipulations/treatment; therapies}

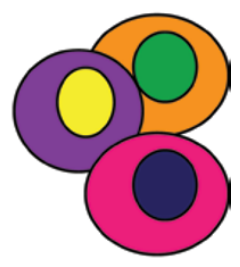

Figure 5 Intrinsic and induced plasticity in CSCs and their progeny. (A) In untreated or early-stage tumors, self-renewing CSCs generate rapidly proliferating tumor progenitors, which may in turn develop into differentiated tumor cells or non-CSCs. This hypothetical developmental pathway perhaps represents the major pathway (indicated by thick arrows) although low levels of spontaneous (or intrinsic) dedifferentiation (indicated by thin arrows) may occur. This model predicts that in the untreated or early-stage tumors, most tumor cells will be partially differentiated tumor progenitors and differentiated tumor cells, with undifferentiated cells representing a minority. The great majority of untreated low-grade breast and prostate cancers, for example, fit this model. (B) Intrinsic plasticity in CSCs manifested as 'molecular mimicry' or GBM CSC transdifferentiation into endothelial cells (EC). (C) During tumor progression, microenvironmental changes, hypoxia, accumulation of inflammatory mediators, together with resultant EMT, may all promote dedifferentiation of non-CSCs (indicated by the thickened reverse arrow). This scenario predicts that in advanced tumors, the undifferentiated, CSC-enriched tumor cells would be in a dynamic equilibrium with more differentiated tumor cells. (D) In vitro experimental manipulations (e.g., mimicking hypoxic conditions, treating cells with EMT-inducers such as cytokines or anti-cancer drugs, overexpressing oncogenic molecules, etc) or persistent tumor therapy in vivo may accentuate dedifferentiation of non-CSCs to stem-like cancer cells (indicated by further thickened reverse arrow) resulting in increased abundance of CSCs.

hypoxia, EMT, inflammatory mediators, and microenvironmental changes can all promote the dedifferentiation of non-CSCs and increase the overall 'stemness' of the tumor (Figure 5C). Recent studies, mostly via in vitro experimental manipulations (Figure 5D), provide support to these possibilities. For example, culturing cancer cells under low $\mathrm{O}_{2}$ tension increases the expression of 'stem- ness' genes and the percentage of phenotypic CSCs [127129]. Experimental EMT and inflammatory cytokines IL-6, IL-8, TGF $\beta$, and TNF $\alpha$ can all promote the manifestation of CSC phenotypes and properties [130-135]. In fact, simply overexpressing certain oncogenic molecules (e.g., Nanog, CD44, Twist, hTERT, etc) is sufficient to reprogram primary non-tumorigenic cells or bulk cancer 
cells into stem-like cancer cells [136-141]. These latter observations [136-141] are consistent with the observations that such 'stemness' molecules are most frequently expressed in undifferentiated tumor cells. Finally, as CSCs constantly interact with their microenvironment, protumorigenic alterations in the microenvironment (e.g., in stromal cells) will likely affect CSC properties and promote plasticity in CSC progeny $[142,143]$.

\section{Concluding remarks and perspectives}

As CSCs have once been thought as a stable and fixed population of 'unique' cells, the recently reported heterogeneity in CSCs and plasticity in non-CSCs have introduced certain confusions and led some investigators to doubt the presence of CSCs and validity of the CSC concept. It might be easier to understand all these phenomena if we simply perceive CSCs as undifferentiated cells and non-CSCs as more differentiated tumor cells. Thus, undifferentiated cancer cells retain some ability to partially or fully (at least phenotypically) differentiate. This is illustrated by the ability of $\mathrm{Lin}^{-} \mathrm{CD} 34^{+} \mathrm{CD} 38^{-}$ LSCs to differentiate into $\mathrm{CD} 38^{+}$leukemic cells and the ability of single tumor cells to differentiate into various phenotypically mature cells in sphere-development assays (see above). On the other hand, as tumorigenic events would generally disrupt the normal differentiation process, 'differentiated' tumor cells may also possess the ability to dedifferentiate or transdifferentiate, especially accompanying tumor progression and in response to cytotoxic therapies. Most current anti-cancer therapeutics primarily target either differentiated or proliferating cancer cells, and, conceivably, will not be effective against undifferentiated cells that are mostly quiescent. Indeed, multiple lines of evidence have demonstrated that CSCs are more resistant to chemotherapeutics, radiation, and immunotherapy $[124,144,145]$ and are endowed with enhanced ability to metastasize [146]. Moreover, many anti-cancer therapies may enrich CSCs [124, 147], perhaps partially by inducing dedifferentiation (Figure 5D). Of great interest, CSCs and non-CSCs may intimately and reciprocally regulate, activate and protect each other. In GBM, the minor subset of glioma cells that carry mutated (i.e., constitutively activated) EGFR behaves like CSCs and preferentially expresses IL-6 and/or LIF (leukemia inhibitory factor), which activate gp130 and wildtype EGFR in the majority of (non-stem) glioma cells and promote their CSC properties [68]. Vice versa, nonCSCs in colon cancers can protect CSCs from the toxicity of chemotherapeutic drugs [148]. These discussions illustrate the potential benefit of combinatorial targeting of both tumor-initiating and differentiated tumor cells
[149]. By simultaneously targeting the tumorigenic and non-tumorigenic populations, both cancer cell heterogeneity and plasticity can be overcome (Figure 5C-5D). Encouragingly, recent data suggest that some commonly used clinical drugs such as docetaxel and metformin may actually be able to root out CSCs $[124,150]$. By discovering more and novel therapeutics that specifically target undifferentiated and dormant tumor cells, coupled with using CSC gene signatures in guiding clinical treatments $[151,152]$, we can hope to achieve much improved cure rate in cancer patients.

\section{Acknowledgments}

The work in the author's lab was supported in part by grants from NIH (R01-ES015888 and 1R21CA 150009), Department of Defense (W81XWH-11-1-0331), Elsa Pardee Foundation and the MDACC Center for Cancer Epigenetics and Laura \& John Arnold Foundation RNA Center Pilot projects.

\section{References}

1 Fuchs E, Horsley V. Ferreting out stem cells from their niches. Nature Cell Biol 2011; 13:513-518.

2 Medema JP, Vermulen L. Microenvironmental regulation of stem cells in intestinal homeostasis and cancer. Nature 2011; 474:318-326.

3 Simons BD, Clevers H. Strategies for homeostatic stem cell self-renewal in adult tissues. Cell 2011; 145:851-862.

4 Li L, Clevers H. Coexistence of quiescent and active adult stem cells in mammals. Science 2010; 327:542-545.

5 Cotsarelis G, Cheng SZ, Dong G, Sun TT, Lavker RM. Existence of slow-cycling limbal epithelial basal cells that can be preferentially stimulated to proliferate: Implications on epithelial stem cells. Cell 1989; 57:201-209.

6 Cotsarelis G, Sun TT, Lavker RM. Label-retaining cells reside in the bulge area of pilosebaceous unit: implications for follicular stem cells, hair cycle, and skin carcinogenesis. Cell 1990; 61:1329-1337.

7 Golebiewska A, Brons NH, Bjerkvig R, Niclou SP. Critical appraisal of the side population assay in stem cell and cancer stem cell research. Cell Stem Cell 2011; 8:136-147.

8 Storms RW, Trujillo AP, Springer JB, et al. Isolation of primitive human hematopoietic progenitors on the basis of aldehyde dehydrogenase activity. Proc Natl Acad Sci USA 1999; 96:9118-9123.

9 Passegué E, Jamieson CH, Ailles LE, Weissman IL. Normal and leukemic hematopoiesis: are leukemias a stem cell disorder or a reacquisition of stem cell characteristics? Proc Natl Acad Sci USA 2003; 100(Suppl 1):11842-11849.

10 Notta F, Doulatov S, Laurenti E, Poeppl A, Jurisica I, Dick JE. Isolation of single human hematopoietic stem cells capable of long-term multilineage engraftment. Science 2011; 333:218221.

11 Majeti R, Park CY, Weissman IL. Identification of a hierarchy of multipotent hematopoietic progenitors in human cord blood. Cell Stem Cell 2007; 1:635-645. 
12 Osawa M, Hanada K, Hamada H, Nakauchi H. Long-term lymphohematopoietic reconstitution by a single CD34-low/ negative hematopoietic stem cell. Science 1996; 273:242-245.

13 Kiel MJ, Yilmaz OH, Iwashita T, Yilmaz OH, Terhorst C, Morrison SJ. SLAM family receptors distinguish hematopoietic stem and progenitor cells and reveal endothelial niches for stem cells. Cell 2005; 121:1109-1121.

14 Xin L, Lawson DA, Witte ON. The Sca-1 cell surface marker enriches for a prostate-regenerating cell subpopulation that can initiate prostate tumorigenesis. Proc Natl Acad Sci USA 2005; 102:6942-6947.

15 Burger PE, Xiong X, Coetzee S, et al. Sca-1 expression identifies stem cells in the proximal region of prostatic ducts with high capacity to reconstitute prostatic tissue. Proc Natl Acad Sci USA 2005; 102:7180-7185.

16 Lawson DA, Xin L, Lukacs RU, Cheng D, Witte ON. Isolation and functional characterization of murine prostate stem cells. Proc Natl Acad Sci USA 2007; 104:181-186.

17 Leong KG, Wang BE, Johnson L, Gao WQ. Generation of a prostate from a single adult stem cell. Nature 2008; 456:804808.

18 Hong SH, Rampalli S, Lee JB, et al. Cell fate potential of human pluripotent stem cells is encoded by histone modifications. Cell Stem Cell 2011; 9:24-36.

19 Bergmann O, Bhardwaj RD, Bernard S, et al. Evidence for cardiomyocyte renewal in humans. Science 2009; 324:98-102.

20 Spalding KL, Arner E, Westermark PO, et al. Dynamics of fat cell turnover in humans. Nature 2008; 453:783-787.

21 Arner P, Bernard S, Salehpour M, et al. Dynamics of human adipose lipid turnover in health and metabolic disease. Nature 2011; 478:110-113.

22 Katoh M, Shaw C, Xu Q, et al. An orderly retreat: Dedifferentiation is a regulated process. Proc Natl Acad Sci USA 2004; 101:7005-7010.

23 Brawley C, Matunis E. Regeneration of male germline stem cells by spermatogonial dedifferentiation in vivo. Science 2004; 304:1331-1334.

24 Dor Y, Brown J, Martinez OI, Melton DA. Adult pancreatic beta-cells are formed by self-duplication rather than stem-cell differentiation. Nature 2004; 429:41-46.

25 Cobaleda C, Jochum W, Busslinger M. Conversion of mature B cells into T cells by dedifferentiation to uncommitted progenitors. Nature 2007; 449:473-477.

26 Heyworth C, Pearson S, May G, Enver T. Transcription factor-mediated lineage switching reveals plasticity in primary committed progenitor cells. EMBO J 2002; 21:3770-3781.

27 Zhou Q, Brown J, Kanarek A, Rajagopal J, Melton DA. In vivo reprogramming of adult pancreatic exocrine cells to betacells. Nature 2008; 455:627-632.

28 Zhou Q, Melton DA. Extreme makeover: converting one cell into another. Cell Stem Cell 2008; 3:382-388.

29 Chambers SM, Studer L. Cell fate plug and play: Direct reprogramming and induced pluripotency. Cell 2011; 145:827830.

30 Pang ZP, Yang N, Vierbuchen T, et al. Induction of human neuronal cells by defined transcription factors. Nature 2011; 476:220-223.

31 Caiazzo M, Dell'Anno MT, Dvorestskova E, et al. Direct generation of functional dopaminergic neurons from mouse and human fibroblasts. Nature 2011; 476:224-227.

32 Yoo AS, Sun AX, Li L, et al. MicroRNA-mediated conversion of human fibroblasts to neurons. Nature 2011; 476:228231.

33 Huang P, He, Z, Ji S, et al. Induction of functional hepatocytelike cells from mouse fibroblasts by defined factors. Nature 2011; 475:386-389.

34 Sekiya S, Suzuki A. Direct conversion of mouse fibroblasts to hepatocyte-like cells by defined factors. Nature 2011; 475:390-393.

35 Collombat P, Xu X, Ravassard P, et al. The ectopic expression of Pax4 in the mouse pancreas converts progenitor cells into $\alpha$ and subsequently $\beta$ cells. Cell 2009; 138:449-462.

36 Kondo T, Raff M. Oligodendrocyte precursor cells reprogrammed to become multipotential CNS stem cells. Science 2000; 289:1754-1757.

37 Yamanaka S. Elite and stochastic models for induced pluripotent stem cell generation. Nature 2009; 460:49-52.

38 Shackleton M, Quintana E, Fearon ER, Morrison SJ. Heterogeneity in cancer: cancer stem cells versus clonal evolution. Cell 2009; 138:822-829.

39 Anderson K, Lutz C, van Delft FW, et al. Genetic variegation of clonal architecture and propagating cells in leukaemia. $\mathrm{Na}$ ture 2011; 469:356-361.

40 Notta F, Mullighan CG, Wang JC, et al. Evolution of human BCR-ABL1 lymphoblastic leukaemia-initiating cells. Nature 2011; 469:362-367.

41 Visvader JE. Cells of origin in cancer. Nature 2011; 469:314322.

42 Lim E, Vaillant F, Wu D, et al. Aberrant luminal progenitors as the candidate target population for basal tumor development in BRCA1 mutation carriers. Nat Med 2009; 15:907-913.

43 Molyneux G, Geyer FC, Magnay FA, et al. BRCAl basal-like breast cancers originate from luminal epithelial progenitors and not from basal stem cells. Cell Stem Cell 2010; 7:403-417.

44 Proia TA, Keller PJ, Gupta PB, et al. Genetic predisposition directs breast cancer phenotype by dictating progenitor cell fate. Cell Stem Cell 2011; 8:149-163.

45 Liu C, Sage JC, Miller MR, et al. Mosaic analysis with double markers reveals tumor cell of origin in glioma. Cell 2011; 146:209-221.

46 Quintana E, Shackleton M, Sabel MS, Fullen DR, Johnson TM, Morrison SJ. Efficient tumour formation by single human melanoma cells. Nature 2008; 456:593-598.

47 Ishizawa K, Rasheed ZA, Karisch R, et al. Tumor-initiating cells are rare in many human tumors. Cell Stem Cell 2010; 7:279-282.

48 Alison MR, Guppy NJ, Lim SML, Nicholson LJ. Finding cancer stem cells: Are aldehyde dehydrogenases fit for purpose? $J$ Pathol 2010; 222:335-344.

49 Pastrana E, Silva-Vargas V, Doetsch F. Eyes wide open: a critical review of sphere-formation as an assay for stem cells. Cell Stem Cell 2011; 8:486-498.

50 Al-Hajj M, Wicha MS, Benito-Hernandez A, Morrison SJ, Clarke MF. Prospective identification of tumorigenic breast cancer cells. Proc Natl Acad Sci USA 2003; 100:3983-3938.

51 Hirschmann-Jax C, Foster AE, Wulf GG, et al. A distinct "side population" of cells with high drug efflux capacity in human tumor cells. Proc Natl Acad Sci USA 2004; 101:14228-14233. 
52 Engelmann K, Shen H, Finn OJ. MCF7 side population cells with characteristics of cancer stem/progenitor cells express the tumor antigen MUC1. Cancer Res 2008; 68:2419-2426.

53 Ginestier C, Hur MH, Charafe-Jauffret E, et al. ALDH1 is a marker of normal and malignant human mammary stem cells and a predictor of poor clinical outcome. Cell Stem Cell 2007; 1:555-567.

54 Charafe-Jauffret E, Ginestier C, Iovino F, et al. Breast cancer cell lines contain functional cancer stem cells with metastatic capacity and a distinct molecular signature. Cancer Res 2009; 69:1302-1313.

55 Pece S, Tosoni D, Confalonieri S, et al. Biological and molecular heterogeneity of breast cancers correlates with their cancer stem cell content. Cell 2010; 140:62-73.

56 Hwang-Verslues WW, Kuo WH, Chang PH, et al. Multiple lineages of human breast cancer stem/progenitor cells identified by profiling with stem cell markers. PLoS One 2009; 4:e8377.

57 Park SY, Lee HE, Li H, Shipitsin M, Gelman R, Polyak K. Heterogeneity for stem cell-related markers according to tumor subtype and histologic stage in breast cancer. Clin Cancer Res 2010; 16:876-887.

58 Deng S, Yang X, Lassus H, et al. Distinct expression levels and patterns of stem cell marker, aldehyde dehydrogenase isoform 1 (ALDH1), in human epithelial cancers. PLoS One 2010; 5:e10277.

59 Meyer MJ, Fleming JM, Lin AF, Hussnain SA, Ginsburg E, Vonderhaar BK. CD $44^{\text {pos }} \mathrm{CD} 49 \mathrm{f}^{\text {hi }} \mathrm{CD} 133 / 2^{\text {hi }}$ defines xenograftinitiating cells in estrogen receptor-negative breast cancer. Cancer Res 2010; 70:4624-4633.

60 Cicalese A, Bonizzi G, Pasi CE, et al. The tumor suppressor p53 regulates polarity of self-renewing divisions in mammary stem cells. Cell 2009; 138:1083-1095.

61 Singh SK, Hawkins C, Clarke ID, et al. Identification of human brain tumour initiating cells. Nature 2004; 432:396-401.

62 Beier D, Hau P, Proescholdt M, et al. CD133(+) and CD133() glioblastoma-derived cancer stem cells show differential growth characteristics and molecular profiles. Cancer Res 2007; 67:4010-4015.

63 Bleau AM, Hambardzumyan D, Ozawa T, et al. PTEN/PI3K/ Akt pathway regulates the side population phenotype and ABCG2 activity in glioma tumor stem-like cells. Cell Stem Cell 2009; 4:226-235.

64 Son MJ, Woolard K, Nam DH, Lee J, Fine HA. SSEA-1 is an enrichment marker for tumor-initiating cells in human glioblastoma. Cell Stem Cell 2009; 4:440-452.

65 Piccirillo SG, Combi R, Cajola L, et al. Distinct pools of cancer stem-like cells coexist within human glioblastomas and display different tumorigenicity and independent genomic evolution. Oncogene 2009; 28:1807-1811.

66 Chen R, Nishimura MC, Bumbaca SM, et al. A hierarchy of self-renewing tumor-initiating cell types in glioblastoma. Cancer Cell 2010; 17:362-375.

67 Mazzoleni S, Politi LS, Pala M, et al. Epidermal growth factor receptor expression identifies functionally and molecularly distinct tumor-initiating cells in human glioblastoma multiforme and is required for gliomagenesis. Cancer Res 2010; 70:7500-7513.

68 Inda MM, Bonavia R, Mukasa A, et al. Tumor heterogeneity is an active process maintained by a mutant EGFR-induced cytokine circuit in glioblastoma. Genes Dev 2010; 24:17311745.

69 Anido J, Sáez-Borderías A, Gonzàlez-Juncà A, et al. TGF- $\beta$ receptor inhibitors target the CD44(high)/Id1(high) gliomainitiating cell population in human glioblastoma. Cancer Cell 2010; 18: 655-668.

70 Lottaz C, Beier D, Meyer K, et al. Transcriptional profiles of CD133+ and CD133- glioblastoma-derived cancer stem cell lines suggest different cells of origin. Cancer Res 2010; 70:2030-2040.

71 Yan X, Ma L, Yi D, et al. A CD133-related gene expression signature identifies an aggressive glioblastoma subtype with excessive mutations. Proc Natl Acad Sci USA 2011; 108:1591-1596.

72 Eyler CE, Wu Q, Yan K, et al. Glioma stem cell proliferation and tumor growth are promoted by nitric oxide synthase-2. Cell 2011; 146:53-66.

73 Broadley KW, Hunn MK, Farrand KJ, et al. Side population is not necessary or sufficient for a cancer stem cell phenotype in glioblastoma multiforme. Stem Cells 2011; 29:452-461.

74 Bonavia R, Inda MM, Cavenee WK, Furnari FB. Heterogeneity maintenance in glioblastoma: a social network. Cancer Res 2011; 71:4055-4060.

75 O'Brien CA, Pollett A, Gallinger S, Dick JE. A human colon cancer cell capable of initiating tumour growth in immunodeficient mice. Nature 2007; 445:106-110.

76 Ricci-Vitiani L, Lombardi DG, Pilozzi E, et al. Identification and expansion of human colon-cancer-initiating cells. Nature 2007; 445:111-115.

77 Todaro M, Alea MP, Di Stefano AB, et al. Colon cancer stem cells dictate tumor growth and resist cell death by production of interleukin-4. Cell Stem Cell 2007; 1:389-402.

78 Dalerba P, Dylla SJ, Park IK, et al. Phenotypic characterization of human colorectal cancer stem cells. Proc Natl Acad Sci USA 2007; 104:10158-10163.

79 Du L, Wang H, He L, et al. CD44 is of functional importance for colorectal cancer stem cells. Clin Cancer Res 2008; 14:6751-6760.

80 Odoux C, Fohrer H, Hoppo T, et al. A stochastic model for cancer stem cell origin in metastatic colon cancer. Cancer Res 2008; 68:6932-6941.

81 Shmelkov SV, Butler JM, Hooper AT, et al. CD133 expression is not restricted to stem cells, and both CD133+ and CD133- metastatic colon cancer cells initiate tumors. J Clin Invest 2008; 118:2111-2120.

82 Vermeulen L, Todaro M, de Sousa Mello F, et al. Aldehyde dehydrogenase 1 is a marker for normal and malignant human colonic stem cells (SC) and tracks SC overpopulation during colon tumorigenesis. Cancer Res 2009; 69:3382-3389.

83 Kemper K, Sprick MR, de Bree M, et al. The AC133 epitope, but not the CD133 protein, is lost upon cancer stem cell differentiation. Cancer Res 2010; 70:719-729.

84 Inoda S, Hirohashi Y, Torigoe T, et al. Cytotoxic T lymphocytes efficiently recognize human colon cancer stem-like cells. Am J Pathol 2011; 178:1805-1813.

85 Wilson BJ, Schatton T, Zhan Q, et al. ABCB5 identifies a therapy-refractory tumor cell population in colorectal cancer patients. Cancer Res 2011; 71:5307-5316. 
86 Medema JP, Vermeulen L. Microenvironmental regulation of stem cells in intestinal homeostasis and cancer. Nature 2011; 474:318-326.

87 Patrawala L, Calhoun T, Schneider-Broussard R, Zhou J-J, Claypool K, Tang DG. Side population (SP) is enriched in tumorigenic, stem-like cancer cells whereas $\mathrm{ABCG} 2^{+}$and $\mathrm{ABCG}^{-}$cancer cells are similarly tumorigenic. Cancer Res 2005; 65:6207-6219.

88 Huss WJ, Gray DR, Greenberg NM, Mohler JL, Smith GJ. Breast cancer resistance protein-mediated efflux of androgen in putative benign and malignant prostate stem cells. Cancer Res 2005; 65:6640-6650.

89 Collins AT, Berry PA, Hyde C, Stower MJ, Maitland NJ. Prospective identification of tumorigenic prostate cancer stem cells. Cancer Res 2005; 65:10946-10951.

90 Patrawala L, Calhoun T, Schneider-Broussard R, et al. Highly purified $\mathrm{CD} 44^{+}$prostate cancer cells from xenograft human tumors are enriched in tumorigenic and metastatic progenitor cells. Oncogene 2006; 25:1696-1708.

91 Patrawala L, Calhoun-Davis T, Schneider-Broussard R, Tang DG. Hierarchical organization of prostate cancer cells in xenograft tumors: The $\mathrm{CD} 44^{+} \alpha 2 \beta 1^{+}$cell population is enriched in tumor-initiating cells. Cancer Res 2007; 67:6796-6805.

92 Miki J, Furusato B, Li H, et al. Identification of putative stem cell markers, CD133 and CXCR4, in hTERT-immortalized primary nonmalignant and malignant tumor-derived human prostate epithelial cell lines and in prostate cancer specimens. Cancer Res 2007; 67:3153-3161.

$93 \mathrm{Gu}$ G, Yuan J, Wills M, Kasper S. Prostate cancer cells with stem cell characteristics reconstitute the original human tumor in vivo. Cancer Res 2007; 67:4807-4815.

94 Li HW, Chen X, Calhoun-Davis T, Claypool K, Tang DG. PC3 Human prostate carcinoma cell holoclones contain selfrenewing tumor-initiating cells. Cancer Res 2008; 68:18201825.

95 Jeter C, Badeaux M, Choy G, et al. Functional evidence that the self-renewal gene $N A N O G$ regulates human tumor development. Stem Cells 2009; 27:993-1005.

96 Dubrovska A, Kim S, Salamone RJ, et al. The role of PTEN/ Akt/PI3K signaling in the maintenance and viability of prostate cancer stem-like cell populations. Proc Natl Acad Sci USA 2009; 106:268-273.

$97 \mathrm{Li} \mathrm{T,} \mathrm{Su} \mathrm{Y,} \mathrm{Mei} \mathrm{Y,} \mathrm{et} \mathrm{al.} \mathrm{ALDH1A1} \mathrm{is} \mathrm{a} \mathrm{marker} \mathrm{for} \mathrm{malignant}$ prostate stem cells and predictor of prostate cancer patients' outcome. Lab Invest 2010; 90:234-244.

98 van den Hoogen C, van der Horst G, Cheung H, et al. High aldehyde dehydrogenase activity identifies tumor-initiating and metastasis-initiating cells in human prostate cancer. Cancer Res 2010; 70:5163-5173.

99 Rajasekhar VK, Studer L, Gerald W, Socci ND, Scher HI. Tumour-initiating stem-like cells in human prostate cancer exhibit increased NF-кB signalling. Nat Commun 2011; 2:162.

100 Liu C, Kelnar K, Liu B, et al. The microRNA miR-34a inhibits prostate cancer stem cells and metastasis by directly repressing CD44. Nature Med 2011; 17:211-215.

101 Ho MM, Ng AV, Lam S, Hung JY. Side population in human lung cancer cell lines and tumors is enriched with stem-like cancer cells. Cancer Res 2007; 67:4827-4833.

102 Eramo A, Lotti F, Sette G, Pilozzi E, Biffoni M. Identification and expansion of the tumorigenic lung cancer stem cell population. Cell Death Differ 2008; 15:504-414.

103 Jiang T, Collins BJ, Jin N, Watkins DN, Brock MV. Achaetescute complex homologue 1 regulates tumor-initiating capacity in human small cell lung cancer. Cancer Res 2009; 69:845854.

104 Bertolini G, Roz L, Perego P, Tortoreto M, Fontanella E. Highly tumorigenic lung cancer $\mathrm{CD}_{13} 3^{+}$cells display stemlike features and are spared by cisplatin treatment. Proc Natl Acad Sci USA 2009; 106:16281-16286.

105 Levina V, Marrangoni A, Wang T, et al. Elimination of human lung cancer stem cells through targeting of the stem cell factor-c-kit autocrine signaling loop. Cancer Res 2010; 70:338346.

106 Eramo A, Haas TL, De Maria R. Lung cancer stem cells: tools and targets to fight lung cancer. Oncogene 2010; 29:46254635.

107 Sullivan JP, Spinola M, Dodge M, et al. Aldehyde dehydrogenase activity selects for lung adenocarcinoma stem cells dependent on notch signaling. Cancer Res 2010; 70:9937-9948.

108 Chiou SH, Wang ML, Chou YT, et al. Coexpression of Oct4 and Nanog enhances malignancy in lung adenocarcinoma by inducing cancer stem cell-like properties and epithelial-mesenchymal transdifferentiation. Cancer Res 2010; 70:1043310444.

109 Leung EL, Fiscus RR, Tung JW, et al. Non-small cell lung cancer cells expressing CD44 are enriched for stem cell-like properties. PLoS One 2010; 5:e14062.

110 Curtis SJ, Sinkevicius KW, Li D, et al. Primary tumor genotype is an important determinant in identification of lung cancer propagating cells. Cell Stem Cell 2010; 7:127-133.

111 Damelin M, Geles KG, Follettie MT, et al. Delineation of a cellular hierarchy in lung cancer reveals an oncofetal antigen expressed on tumor-initiating cells. Cancer Res 2011; 71:4236-4246.

112 Lapidot T, Sirard C, Vormoor J, et al. A cell initiating human acute myeloid leukaemia after transplantation into SCID mice. Nature 1994; 367:645-648.

113 Bonnet D, Dick JE. Human acute myeloid leukemia is organized as a hierarchy that originates from a primitive hematopoietic cell. Nat Med 1997; 3:730-737.

114 Hope KJ, Jin L, Dick JE. Acute myeloid leukemia originates from a hierarchy of leukemic stem cell classes that differ in self-renewal capacity. Nat Immunol 2004; 5:738-743.

115 Sarry JE, Murphy K, Perry R, et al. Human acute myelogenous leukemia stem cells are rare and heterogeneous when assayed in NOD/SCID/IL2R $\gamma c$-deficient mice. J Clin Invest 2011; 121:384-395.

116 Shipitsin M, Campbell LL, Argani P, et al. Molecular definition of breast tumor heterogeneity. Cancer Cell 2007; 11: 259-273.

117 Park SY, Gönen M, Kim HJ, Michor F, Polyak K. Cellular and genetic diversity in the progression of in situ human breast carcinomas to an invasive phenotype. J Clin Invest 2010; 120:636-644.

118 Lotem J, Sachs L. Epigenetics and the plasticity of differentiation in normal and cancer stem cells. Oncogene 2006; 25:7663-7672.

119 Hendrix MJ, Seftor EA, Hess AR, Seftor RE. Molecular plas- 
ticity of human melanoma cells. Oncogene 2003; 22:30703075.

120 Casal C, Torres-Collado AX, Plaza-Calonge Mdel C, et al. ADAMTS1 contributes to the acquisition of an endotheliallike phenotype in plastic tumor cells. Cancer Res 2010; 70:4676-4686.

121 Wang R, Chadalavada K, Wilshire J, et al. Glioblastoma stem-like cells give rise to tumour endothelium. Nature 2010; 468:829-833.

122 Ricci-Vitiani L, Pallini R, Biffoni M, et al. Tumour vascularization via endothelial differentiation of glioblastoma stemlike cells. Nature 2010; 468:824-828.

123 Sharma SV, Lee DY, Li B, et al. A chromatin-mediated reversible drug-tolerant state in cancer cell subpopulations. Cell 2010; 141:69-80.

124 Yan H, Chen X, Zhang Q, et al. Drug-tolerant cancer cells show reduced tumor-initiating capacity: Depletion of CD44+ cells and evidence for epigenetic mechanisms. PLoS One 2011; 6:e24397.

125 Chaffer CL, Brueckmann I, Scheel C, et al. Normal and neoplastic nonstem cells can spontaneously convert to a stem-like state. Proc Natl Acad Sci USA 2011; 108:7950-7955.

126 Gupta PB, Fillmore CM, Jiang G, et al. Stochastic state transitions give rise to phenotypic equilibrium in populations of cancer cells. Cell 2011; 146:633-644.

127 Das B, Tsuchida R, Malkin D, et al. Hypoxia enhances tumor stemness by increasing the invasive and tumorigenic side population fraction. Stem Cells 2008; 26:1818-1830.

128 Mathieu J, Zhang Z, Zhou W, et al. HIF induces human embryonic stem cell markers in cancer cells. Cancer Res 2011; 71:4640-4652.

129 Koh MY, Lemos R Jr, Liu X, Powis G. The hypoxia-associated factor switches cells from HIF- $1 \alpha$ - to HIF- $2 \alpha$-dependent signaling promoting stem cell characteristics, aggressive tumor growth and invasion. Cancer Res 2011; 71:4015-4027.

130 Mani SA, Guo W, Liao MJ, et al. The epithelial-mesenchymal transition generates cells with properties of stem cells. Cell 2008; 133:704-715.

131 Santisteban M, Reiman JM, Asiedu MK, et al. Immuneinduced epithelial to mesenchymal transition in vivo generates breast cancer stem cells. Cancer Res 2009; 69:2887-2895.

132 Iliopoulos D, Hirsch HA, Struhl K. An epigenetic switch involving NF-kappaB, Lin28, Let-7 MicroRNA, and IL6 links inflammation to cell transformation. Cell 2009; 139:693-706.

133 Iliopoulos D, Lindahl-Allen M, Polytarchou C, Hirsch HA, Tsichlis PN, Struhl K. Loss of miR-200 inhibition of Suz12 leads to polycomb-mediated repression required for the formation and maintenance of cancer stem cells. Mol Cell 2010; 39:761-772.

134 Asiedu MK, Ingle JN, Behrens MD, Radisky DC, Knutson KL. TGF $\beta / T N F \alpha$-mediated epithelial-mesenchymal transition generates breast cancer stem cells with a claudin-low phenotype. Cancer Res 2011; 71:4707-4719.

135 Iliopoulos D, Hirsch HA, Wang G, Struhl K. Inducible formation of breast cancer stem cells and their dynamic equilibrium with non-stem cancer cells via IL6 secretion. Proc Natl Acad Sci USA 2011; 108:1397-1402.

136 Jeter CR, Liu B, Liu X, et al. NANOG promotes cancer stem cell characteristics and prostate cancer resistance to androgen deprivation. Oncogene 2011; 30:3833-3845.

137 Arzumanyan A, Friedman T, Ng IO, Clayton MM, Lian Z, Feitelson MA. Does the hepatitis B antigen HBx promote the appearance of liver cancer stem cells? Cancer Res 2011; 71:3701-3708.

138 Su YJ, Lai HM, Chang YW, Chen GY, Lee JL. Direct reprogramming of stem cell properties in colon cancer cells by CD44. EMBO J 2011; 30:3186-3199.

139 Scaffidi P, Misteli T. In vitro generation of human cells with cancer stem cell properties. Nat Cell Biol 2011; 13:10511061.

140 Hwang WL, Yang MH, Tsai ML, et al. SNAIL regulates interleukin-8 expression, stem cell-like activity, and tumorigenicity of human colorectal carcinoma cells. Gastroenterology 2011; 141:279-291.

141 Paranjape AN, Mandal T, Mukherjee G, Kumar MV, Sengupta K, Rangarajan A. Introduction of SV40ER and hTERT into mammospheres generates breast cancer cells with stem cell properties. Oncogene 2011 Aug 29. doi: 10.1038/ onc. 2011.378

142 Bissell MJ, Labarge MA. Context, tissue plasticity, and cancer: are tumor stem cells also regulated by the microenvironment? Cancer Cell 2005; 7:17-23.

143 Liu S, Ginestier C, Ou SJ, et al. Breast cancer stem cells are regulated by mesenchymal stem cells through cytokine networks. Cancer Res 2011; 71:614-624.

$144 \mathrm{Li}$ X, Lewis MT, Huang J, et al. Intrinsic resistance of tumorigenic breast cancer cells to chemotherapy. J Natl Cancer Inst 2008; 100:672-679.

145 Reim F, Dombrowski Y, Ritter C, et al. Immunoselection of breast and ovarian cancer cells with trastuzumab and natural killer cells: selective escape of CD $44^{\text {high }} / \mathrm{CD} 24^{\text {low }} / \mathrm{HER} 2^{\text {low }}$ breast cancer stem cells. Cancer Res 2009; 69:8058-8066.

146 Liu H, Patel MR, Prescher JA, et al. Cancer stem cells from human breast tumors are involved in spontaneous metastases in orthotopic mouse models. Proc Natl Acad Sci USA 2010; 107:18115-18120.

147 Yu F, Yao H, Zhu P, et al. let-7 regulates self renewal and tumorigenicity of breast cancer cells. Cell 2007; 131:11091123.

148 Emmink BL, Van Houdt WJ, Vries RG, et al. Differentiated human colorectal cancer cells protect tumor-initiating cells from irinotecan. Gastroenterology 2011; 141:269-278.

149 Dubrovska A, Elliott J, Salamone RJ, et al. Combination therapy targeting both tumor-initiating and differentiated cell populations in prostate carcinoma. Clin Cancer Res 2010; 16:5692-5702.

150 Hirsch HA, Iliopoulos D, Tsichlis PN, Struhl K. Metformin selectively targets cancer stem cells, and acts together with chemotherapy to block tumor growth and prolong remission. Cancer Res 2009; 69:7507-7511.

151 Shats I, Gatza ML, Chang JT, et al. Using a stem cell-based signature to guide therapeutic selection in cancer. Cancer Res 2011; 71:1772-1780.

152 Eppert K, Takenaka K, Lechman ER, et al. Stem cell gene expression programs influence clinical outcome in human leukemia. Nat Med 2011; 17:1086-1093. 